\title{
Renal Transport Kinetics of Furosemide in the Isolated Perfused Rat Kidney
}

\author{
Ling-Jar Lee, ${ }^{1}$ Jack A. Cook, ${ }^{1}$ and David E. Smith ${ }^{1,2}$ \\ Received October 23, 1985-Final January 29, 1986
}

\begin{abstract}
Direct quantitative data and corresponding theory are provided for the effect of protein binding on the renal transport of furosemide. Drig studies were performed with various combinations of bovine serum albumin and dextran. This resulted in a percent unbound ( $\mathrm{fu}$ ) of furosemide ranging from 0.785 to $85.8 \%$. The corrected renal (CLr/GFR) and secretion (CLs/GFR) clearances of furosemide were observed to increase with percent free, but in a nonproportional manner. Plots of $\mathrm{CLr} / \mathrm{GFR}$ or CLs/GFR vs. fu appeared to have a prominent y intercept as well as a convex ascending curve. In addition, the excretion ratio [ER $=\mathrm{CLr} /(\mathrm{fu} \cdot \mathrm{GFR})]$ was reduced from 60.8 to 8.72 as fu increased. Overall, the data were best fitted to a model in which two Michaelis-Menten terms wre used to describe renal tubular transport, and secretion was dependent upon free drug concentrations in the perfusate. The results demonstrate that the renal mechanisms of furosemide excretion are more complex than previously reported and that active secretion may involve two different transport systems over the concentration range studied.
\end{abstract}

KEY WORDS: furosemide; protein binding; renal and secretion clearances; excretion ratio.

\section{INTRODUCTION}

Over the past 10 years, the relationship between the mathematical description and biological determinants of hepatic drug clearance has been reasonably well defined and experimentally verified. These determinants include such factors as hepatic blood flow, the activity of the overall elimination process (intrinsic clearance), drug binding in the blood, and the anatomic arrangement of the hepatic circulation. On the other hand, integration of direct quantitative data and corresponding theory with respect to renal drug clearance is rather limited (1-4). In particular, the precise

\footnotetext{
This work was supported in part by the Upjohn Research Fund, College of Pharmacy, University of Michigan. During the course of this work, J.A.C. was supported by a Lilly Endowment Fellowship, grant 830192.

${ }^{1}$ College of Pharmacy, University of Michigan, Ann Arbor, Michigan 48109-1065.

${ }^{2}$ To whom correspondence should be addressed.
} 
role of changes in plasma protein binding on the secretion kinetics of a drug is vague due to the complexity of renal excretion (4-7).

The proposed studies will systematically evaluate, using the isolated, perfused rat kidney, the effect of protein binding on the renal transport of furosemide. This diuretic represents a model compound in that it is highly plasma protein bound $(>90 \%)$, demonstrates a net active secretion from the renal tubules, and is predominantly eliminated by the renal route in humans $(8,9)$. In addition, furosemide is extensively used in various patient populations (10-12) and exerts its pharmacodynamic response from the luminal surface of the nephron (13-15). Therefore, from a clinical as well as a mechanistic standpoint, it is important to determine whether protein binding is a limiting factor in furosemide secretion.

\section{METHODS}

\section{Perfusate}

The initial perfusate volume was $100 \mathrm{ml}(p \mathrm{H} \mathrm{7.4})$. It consisted of Krebs-Henseleit bicarbonate buffer (16) containing Fraction $V$ bovine serum albumin (Miles Laboratories, Elkhart, IN), clinical-grade dextran (molecular weight 60,000-90,000; Sigma Chemical Co., St. Louis, MO), or a combination of the two, as well as glucose $(0.1 \%),{ }^{14} \mathrm{C}$-inulin $(2.5 \mu \mathrm{Ci}$, specific activity $2.0 \mu \mathrm{Ci} / \mathrm{mg}$; ICN Biomedicals, Irvine, CA), and eight L-amino acids (Sigma Chemical Co., St. Louis, MO) (17).

\section{Surgical Procedure}

The development of the isolated, perfused rat kidney was based upon the methods of Nishiitsutsuji-Uwo et al. (18) and Bowman (19). Male Sprague-Dawley rats (Charles River Breeding Laboratories, Wilmington, MA), $350-450 \mathrm{~g}$, were anesthetized with sodium pentobarbital $(\sim 50 \mathrm{mg} / \mathrm{kg})$. The left superficial femoral vein was exposed and $100 \mathrm{mg}$ of mannitol and 200 units of heparin were administered. A midline incision was then made and the major abdominal blood vessels were isolated. A ligature was passed around the right renal artery, and distal and proximal ligatures were placed around the mesenteric artery. The right ureter was catheterized with PE-10 polyethylene tubing. The right renal artery was cannulated via the mesenteric artery and the hemostat holding back the perfusate was released just before the cannula entered the renal artery. The whole kidney was then excised, trimmed of adhering tissue, and immediately transferred to a recirculating perfusion apparatus, completely enclosed in a temperature-controlled 
$\left(37^{\circ} \mathrm{C}\right)$ Plexiglas chamber. Perfusion pressure in the renal artery was controlled by monitoring the manometer and adjusting the speed of the perfusion pump. A correction was made for the intrinsic apparatus pressure.

\section{Experimental Design}

Various combinations of bovine serum albumin (BSA) and dextran (D) were used in order to produce a wide range of values for the protein binding of furosemide. Two rats were studied at each particular combination $(6.0 \%$ BSA $+0 \%$ D; $4.0 \%$ BSA $+1.33 \% \mathrm{D} ; 3.0 \% \mathrm{BSA}+2.0 \% \mathrm{D} ; 2.0 \%$ $\mathrm{BSA}+2.67 \% \mathrm{D} ; 1.0 \% \mathrm{BSA}+3.33 \% \mathrm{D} ; 0.5 \% \mathrm{BSA}+3.67 \% \mathrm{D} ; 0.25 \% \mathrm{BSA}+$ $3.83 \% \mathrm{D} ; 0.08 \% \mathrm{BSA}+3.94 \% \mathrm{D} ; 0.025 \% \mathrm{BSA}+3.98 \% \mathrm{D}$; and $0 \% \mathrm{BSA}+$ $4.0 \% \mathrm{D})$ for a total of 20 experiments. The initial perfusate concentration of furosemide was $100 \mu \mathrm{M}$.

After a 20 -min equilibration period, furosemide was introduced as a bolus into the recirculating perfusate. An additional $20 \mathrm{~min}$ was then allowed for drug distribution (2). The subsequent experimental time was divided into 10-min urine collection periods for the measurement of kidney function and drug disposition parameters. The urine volume was measured with a tuberculin syringe and the $p \mathrm{H}$ was determined immediately. Perfusate $(1.5 \mathrm{ml})$ was sampled at the midpoint time of each urine collection. The composition of recirculating perfusate was maintained by isovolumetric replacement of urine loss with buffer and perfusate sampling loss with perfusate (no drug present). Kidney function was determined by the fractional excretion of sodium and glucose, and by glomerular filtration rate $(G F R)$. The renal clearance of inulin was taken to represent GFR. Renal clearances were calculated for furosemide and inulin by dividing the urinary excretion rate of the substance by its perfusate concentration at the midpoint time interval.

\section{Analytical}

Perfusate and urine samples containing furosemide were analyzed by a sensitive and specific HPLC assay developed by Smith et al. (20). This method utilizes a direct injection technique where the only cleanup procedure involves the precipitation of albumin with acetonitrile. Representative urine samples were also analyzed for the glucuronide metabolite of furosemide and 2-amino-4-chloro-5-sulfamylanthranilic acid (CSA), as described previously (20). This is necessary since intrarenal metabolism can obscure the correct interpretation of renal clearance mechanisms (6). These assays were modified to reflect the smaller volume requirement $(0.05 \mathrm{ml})$ for perfusate and urine samples obtained during the isolated, perfused rat kidney experiments. 
Radioactivity measurements for ${ }^{14} \mathrm{C}$-inulin were performed on an LS 9000 liquid scintillation counter (Beckman Instruments, Irvine, CA) using an external standard method for quench correction. Sodium was determined with a model 455 flame photometer (Corning Medical and Scientific, Medfield, MA) and glucose was determined colorimetrically using a commercial kit (Sigma Chemical Co., St. Louis, MO).

\section{Protein Binding}

The binding of furosemide to albumin in the recirculating perfusate was determined using an equilibrium dialysis method $(20,21)$. One-half $\mathrm{ml}$ of perfusate was dialyzed against an equal volume of isotonic phosphate buffer $(0.067 \mathrm{M}, p \mathrm{H} 7.4)$ at $37^{\circ} \mathrm{C}$ for $5 \mathrm{hr}$ using Spectrapor 2 membrane tubing (Spectrum Medical Industries, Los Angeles, CA). Preliminary studies indicated that $5 \mathrm{hr}$ was a sufficient amount of time for equilibrium to be reached at the various albumin concentrations employed in these experiments. Dialyzed buffer $(0.3 \mathrm{ml})$ was then mixed with the internal standard, sodium phenobarbital, and injected into the HPLC system, as described previously (20).

Furosemide exhibited a nonlinear binding in several experiments and values for percent free were determined accordingly $(22,23)$. Since the initial volumes of the perfusate and buffer compartments were equal prior to dialysis, the volume-corrected bound concentration in the post dialysis perfusate $\left(C b^{\prime \prime}\right)$ was calculated as

$$
C b^{\prime \prime}=C p-2 \cdot C f^{\prime}
$$

where $C p$ represents the measured total plasma concentration of furosemide prior to dialysis and $C f^{\prime}$ represents the measured unbound concentration of furosemide in buffer after dialysis. This equation was developed to correct for the osmotic water shift that occurs during equilibrium dialysis, resulting in lower protein and bound drug concentrations in the postdialysis plasma compartment (23).

The appropriate bound $\left(C b^{\prime \prime}\right)$ and free $\left(C f^{\prime}\right)$ equilibrium concentrations of furosemide were then best-fitted to a protein binding model which incorporates a single Langmuir term plus two linear terms:

$$
C b^{\prime \prime}=\frac{P_{1} \cdot B S A \cdot C f^{\prime}}{P_{2}+C f^{\prime}}+P_{3} \cdot B S A \cdot C f^{\prime}+P_{4}(870-B S A) \cdot 0.561 C f^{\prime}
$$

$P_{1}, P_{2}, P_{3}$, and $P_{4}$ represent the binding parameters, $B S A$ represents the concentration of bovine serum albumin, and (870-BSA) $\cdot 0.561$ represents the concentration of dextran in the perfusate for a given concentration of $B S A$, expressed in $\mu \mathrm{M}$ units. Dextran was included in the binding model 
since in vitro experiments confirmed that approximately $10-15 \%$ of furosemide is bound to $4 \%$ of this polymer.

Once the binding parameters are known, the unbound $(C f)$ and bound $(\mathrm{Cb})$ concentrations in the original perfusate sample can be determined by simultaneous solution of Eq. (2) and the relationship $C p=C f+C b$ (22). This results in the equation

$$
\begin{aligned}
& {\left[1+B S A \cdot P_{3}+P_{4}(870-B S A) \cdot 0.561\right] C f^{2}} \\
& \quad+\left[P_{2}+B S A \cdot P_{1}+B S A \cdot P_{2} P_{3}+P_{2} P_{4}(870-B S A) \cdot 0.561-C P\right] C f \\
& \quad-P_{2} C p=0 .
\end{aligned}
$$

in which $C f$ can be obtained by finding the positive root of the quadratic equation (3) for given values of $C p$ and $B S A$.

The percent of unbound furosemide in the original recirculating perfusate can now be determined by

$$
f u(\%)=100(C f / C p)
$$

\section{Renal Transport Models}

For a compound of low extraction (plasma flow to the kidney $\gg$ intrinsic renal tubular secretion), Levy (4) proposed the following models to express the relationship between renal drug clearance $(C L r)$ and free fraction $(f u)$ :

$$
\begin{aligned}
& C L r=f u \cdot[G F R \cdot(1-F)+K s \cdot(1-F)] \\
& C L r=f u \cdot G F R \cdot(1-F)+K s^{\prime} \cdot(1-F)
\end{aligned}
$$

where $F$ represents the tubular reabsorption fraction, $K s$ the renal tubular secretion clearance referenced to unbound drug concentrations in plasma, and $K s^{\prime}$ the renal tubular secretion clearance referenced to total drug concentrations in plasma. Both equations assume that renal tubular secretion remains linear over the concentration range studied and that the tubular reabsorption fraction is constant and involves the passive diffusion of nonionized drug molecules from the distal region of the renal tubules. Accordingly, if the rate of renal tubular secretion is a function of the unbound drug, then a plot of renal clearance versus free fraction in plasma should be linear and intersect the origin [Eq. (5)]. If the rate of renal tubular secretion is a function of the total drug, then a plot of renal clearance versus free fraction should be linear and have a positive intercept [Eq. (6)]. However, application of these relationships to furosemide revealed that Eqs. (5) and (6) were not appropriate to describe our data (see results). Therefore, the theoretical models below were derived. 
In general, the excretion of a drug from the plasma into the urine is expressed by

$$
U \cdot \dot{V}=G F R \cdot C f+S-A
$$

where $U$ is the drug concentration in urine, $\dot{V}$ is the urine flow rate, $S$ is the rate of secretion, and $A$ is the rate of reabsorption. By assuming that two Michaelis-Menten terms are needed to describe a drug's rate of active secretion, and that secretion is dependent upon free drug concentrations, we can express $S$ and $A$ by

$$
\begin{aligned}
& S=\frac{V m_{1} \cdot C f}{K m_{1}+C f}+\frac{V m_{2} \cdot C f}{K m_{2}+C f} \\
& A=F(G F R \cdot C f+S)
\end{aligned}
$$

where $V m_{1}$ and $K m_{1}$ are the maximum velocity of secretion and the Michaelis constant, respectively, for the low-affinity, high-capacity transport system, and $\mathrm{Vm}_{2}$ and $\mathrm{Km}_{2}$ are the maximum velocity of secretion and the Michaelis constant, respectively, for the high-affinity, low-capacity transport system. Therefore, the renal clearance becomes

$$
C L r=\left(G F R \cdot f u+\frac{V m_{1} \cdot f u}{K m_{1}+C f}+\frac{V m_{2} \cdot f u}{K m_{2}+C f}\right)(1-F)
$$

The excretion ratio $(E R)$ is then obtained by dividing each side of Eq. (10) by $f u \cdot G F R$,

$$
E R=\left(1+\frac{V m_{1} / G F R}{K m_{1}+C f}+\frac{V m_{2} / G F R}{K m_{2}+C f}\right)(1-F)
$$

Since the second transport system is of a high-affinity, low-capacity nature, $C f \gg K m_{2}$, and Eq. (11) simplifies to

$$
E R=\left(1+\frac{V m_{1} / G F R}{K m_{1}+C f}+\frac{V m_{2} / G F R}{C f}\right)(1-F)
$$

The urinary excretion rate $(U \cdot \dot{V})$ was derived by substituting $S$ [Eq. (8)] and $\boldsymbol{A}$ [Eq. (9)] into Eq. (7) and then applying the same assumptions as in Eq. (12) $\left(C f \gg K m_{2}\right)$ :

$$
U \cdot \dot{V}=\left(G F R \cdot C f+\frac{V m_{1} \cdot C f}{K m_{1}+C f}+V m_{2}\right)(1-F)
$$

\section{Statistical Analysis}

Experimental data were fitted to Eqs. (2), (12), and (13) using the nonlinear least-squares regression program NONLIN (24). The parameter estimates ( \pm standard deviation) were obtained using a weighting factor of unity and the goodness of the fit was determined by $R^{2}, C O R$, and by visual examination of the residuals. 
Table I. Physiological Function of the Isolated Perfused Rat Kidney ${ }^{a}$

\begin{tabular}{|c|c|c|c|c|c|c|c|c|c|c|}
\hline & \multicolumn{10}{|c|}{ Parameter value at given concentration of $\mathrm{BSA}^{b}$} \\
\hline & $6 \%$ & $4 \%$ & $3 \%$ & $2 \%$ & $1 \%$ & $0.5 \%$ & $0.25 \%$ & $0.08 \%$ & $0.025 \%$ & $0 \%$ \\
\hline $\begin{array}{l}\text { GFR } \\
(\mathrm{ml} / \mathrm{min})\end{array}$ & $\begin{array}{c}0.995 \\
(0.136)\end{array}$ & $\begin{array}{c}0.844 \\
(0.081)\end{array}$ & $\begin{array}{c}0.816 \\
(0.198)\end{array}$ & $\begin{array}{c}0.880 \\
(0.262)\end{array}$ & $\begin{array}{c}0.847 \\
(0.123)\end{array}$ & $\begin{array}{c}0.594 \\
(0.081)\end{array}$ & $\begin{array}{c}0.777 \\
(0.198)\end{array}$ & $\begin{array}{c}0.779 \\
(0.078)\end{array}$ & $\begin{array}{c}0.670 \\
(0.109)\end{array}$ & $\begin{array}{c}0.576 \\
(0.095)\end{array}$ \\
\hline $\begin{array}{l}F E \text { sodium } \\
(\%)\end{array}$ & $\begin{array}{l}16.5 \\
(1.9)\end{array}$ & $\begin{array}{l}13.3 \\
(4.7)\end{array}$ & $\begin{array}{l}16.1 \\
(6.2)\end{array}$ & $\begin{array}{l}13.8 \\
(5.6)\end{array}$ & $\begin{array}{l}11.6 \\
(3.0)\end{array}$ & $\begin{array}{l}18.4 \\
(1.7)\end{array}$ & $\begin{array}{l}10.9^{\prime} \\
(3.9)\end{array}$ & $\begin{array}{l}15.4 \\
(3.2)\end{array}$ & $\begin{array}{l}16.0 \\
(1.5)\end{array}$ & $\begin{array}{l}22.8 \\
(2.8)\end{array}$ \\
\hline $\begin{array}{c}F E \text { glucose } \\
(\%)\end{array}$ & $\begin{array}{c}1.70 \\
(0.43)\end{array}$ & $\begin{array}{c}4.59 \\
(1.53)\end{array}$ & $\begin{array}{c}3.43 \\
(2.27)\end{array}$ & $\begin{array}{c}4.14 \\
(2.25)\end{array}$ & $\begin{array}{c}5.33 \\
(2.67)\end{array}$ & $\begin{array}{c}4.69 \\
(0.93)\end{array}$ & $\begin{array}{c}3.59 \\
(1.08)\end{array}$ & $\begin{array}{c}5.54 \\
(1.16)\end{array}$ & $\begin{array}{c}5.31 \\
(0.64)\end{array}$ & $\begin{array}{c}7.91 \\
(1.39)\end{array}$ \\
\hline $\begin{array}{l}\text { Perfusate flow } \\
(\mathrm{ml} / \mathrm{min})\end{array}$ & $\begin{array}{l}42.8 \\
(4.3)\end{array}$ & $\begin{array}{l}35.4 \\
(5.5)\end{array}$ & $\begin{array}{l}34.2 \\
(1.2)\end{array}$ & $\begin{array}{l}24.8 \\
(1.1)\end{array}$ & $\begin{array}{l}23.9 \\
(1.7)\end{array}$ & $\begin{array}{l}23.0 \\
(0.13)\end{array}$ & $\begin{array}{l}27.5 \\
(5.4)\end{array}$ & $\begin{array}{l}24.6 \\
(0.2)\end{array}$ & $\begin{array}{l}24.7 \\
(0.1)\end{array}$ & $\begin{array}{l}27.8 \\
(2.2)\end{array}$ \\
\hline $\begin{array}{l}\text { Perfusion } \\
\text { pressure } \\
\text { (mm Hg) }\end{array}$ & $\begin{array}{l}91.8 \\
(1.2)\end{array}$ & $\begin{array}{l}95.6 \\
(1.3)\end{array}$ & $\begin{array}{l}96.4 \\
(6.6)\end{array}$ & $\begin{array}{l}97.5 \\
(2.2)\end{array}$ & $\begin{array}{l}93.3 \\
(1.7)\end{array}$ & $\begin{array}{l}98.8 \\
(7.2)\end{array}$ & $\begin{array}{l}93.7 \\
(3.5)\end{array}$ & $\begin{array}{l}94.6 \\
(4.0)\end{array}$ & $\begin{array}{l}96.1 \\
(6.4)\end{array}$ & $\begin{array}{l}94.6 \\
(1.6)\end{array}$ \\
\hline$N^{c}$ & 15 & 18 & 17 & 14 & 18 & 18 & 15 & 16 & 14 & 10 \\
\hline
\end{tabular}

${ }^{a}$ Data reported as mean $\pm \mathrm{SD}$.

${ }^{b}$ Furosemide was present in the perfusate at an initial concentration of $100 \mu \mathrm{M}$. Dextran was present in the perfusate as indicated in Table II.

${ }^{c}$ Number of clearance periods studied in two rat perfusions.

\section{RESULTS}

\section{Physiological Function of the Perfused Kidney}

Presented in Table I are the functional characteristics of perfusate experiments containing furosemide when carried out at various albumin/dextran combinations. Kidney function as reflected by GFR and fractional glucose excretion ( $F E$ glucose) were within the normal range of values for this technique $(2,3,17,25)$, although a general reduction of $G F R$ and perfusate flow was observed as dextran concentrations became greater. Since furosemide is a "loop-diuretic," a fractional sodium excretion (FEsodium) of $12-23 \%$ is to be expected (26). Nevertheless, the proximal tubule retains considerable capacity for transport, as evidenced by the relatively low values for $F E$ glucose in all experiments (1). Predrug functional parameters were $0.988 \mathrm{ml} / \mathrm{min}$ (GFR), $7.55 \%$ (FEsodium), and $0.96 \%(F E$ glucose $)$ at $6 \% \mathrm{BSA}+0 \% \mathrm{D}$; and $0.722 \mathrm{ml} / \mathrm{min}(G F R), 7.97 \%$ (FEsodium), and $2.34 \%$ ( $F E$ glucose) at $0 \% \mathrm{BSA}+4 \% \mathrm{D}$.

\section{Protein Binding}

Using the input values of $\mathrm{Cb}^{\prime \prime}$ as the dependent variable and $B S A$ and $C f^{\prime}$ as the two independent varibles, the binding parameters of Eq. (2) were estimated as $P_{1}=0.44(0.14), P_{2}=2.92(0.86) \mu \mathrm{M}, P_{3}=0.022(0.013) \mu \mathrm{M}^{-1}$, and $P_{4}=0.00034(0.00020) \mu \mathrm{M}^{-1}\left(R^{2}=0.980 ; C O R=0.975\right)$. The parameter estimates and the application of Eqs. (3) and (4) allowed for the calculation of the percent unbound of furosemide in the original perfusate samples. Table II demonstrates that the percent unbound of furosemide 
Table II. Composition of Perfusate and Corresponding Fraction Unbound of Furosemide ${ }^{a}$

\begin{tabular}{lcc}
\hline $\begin{array}{c}\text { BSA } \\
(\%)\end{array}$ & $\begin{array}{c}\text { Dextran } \\
(\%)\end{array}$ & $\begin{array}{c}\text { Fraction unbound } \\
(\%)\end{array}$ \\
\hline 6 & 0 & 0.785 \\
& & $(0.056)$ \\
4 & 1.33 & 1.24 \\
& & $(0.06)$ \\
3 & 2.00 & $(0.14)$ \\
& & 3.04 \\
2 & 2.67 & $(0.26)$ \\
& 3.33 & 6.51 \\
1 & 3.67 & $1.28)$ \\
& & 15.4 \\
0.5 & 3.83 & 26.8 \\
& & $(7.2)$ \\
0.25 & 3.94 & 48.2 \\
& & $(10.8)$ \\
0.08 & 3.98 & 72.9 \\
& & $(4.4)$ \\
0.025 & 4 & 85.8 \\
& & $(0.0)$ \\
\hline
\end{tabular}

${ }^{a}$ Data reported as mean \pm SD. Fraction unbound was determined for each clearance period of the recirculating perfusate. Furosemide was present initially at a concentration of $100 \mu \mathrm{M}$. Refer to Table I for number of clearance periods studied in each group.

could be manipulated from very low values $(0.785 \%)$ to almost $90 \%$ free drug under the albumin/dextran concentrations employed.

\section{Furosemide Metabolism}

Using a specific HPLC assay, we were unable to detect a glucuronide metabolite of furosemide or CSA in any of the samples tested. This lack of biotransformation or degradation during the kidney perfusion experiments is in agreement with a similar study where at least $97 \%$ of the radioactivity present in perfusate or urine samples was reported as unchanged furosemide (2).

\section{Furosemide Excretion}

In Table III, clearance values have been corrected for GFR to take into account the varying functional capacity among kidney preparations. The corrected renal and secretion clearances of furosemide are observed 
Table III. Furosemide Clearance in the Perfused Rat Kidney ${ }^{a}$

\begin{tabular}{lccc}
\hline $\begin{array}{l}\text { BSA } \\
(\%)\end{array}$ & $C L r / G F R$ & $C L s / G F R$ & $C L r / f u \cdot G F R$ \\
\hline 6 & 0.472 & 0.464 & 60.8 \\
& $(0.057)$ & $(0.057)$ & $(10.7)$ \\
4 & 0.512 & 0.500 & 41.7 \\
& $(0.074)$ & $(0.072)$ & $(6.9)$ \\
3 & 0.605 & 0.586 & 35.5 \\
& $(0.197)$ & $(0.197)$ & $(14.1)$ \\
2 & 0.718 & 0.691 & 23.6 \\
& $(0.203)$ & $(0.203)$ & $(7.5)$ \\
1 & 1.32 & 1.25 & 21.2 \\
& $(0.31)$ & $(0.31)$ & $(7.1)$ \\
0.5 & 2.36 & 2.22 & 16.6 \\
& $(0.48)$ & $(0.48)$ & $(6.3)$ \\
0.25 & 4.17 & 3.94 & 17.1 \\
& $(0.90)$ & $(0.93)$ & $(6.7)$ \\
0.08 & 7.10 & 6.55 & 15.9 \\
& $(1.88)$ & $(1.92)$ & $(6.2)$ \\
0.025 & 11.2 & 10.5 & 15.7 \\
& $(3.4)$ & $(3.4)$ & $(5.4)$ \\
0 & 7.48 & 6.55 & 8.72 \\
& $(1.29)$ & $(1.27)$ & $(1.50)$ \\
\hline
\end{tabular}

${ }^{a}$ Data reported as mean $\pm S D$. Dextran was present in the perfusate as indicated in Table II. Furosemide was present at an initial concentration of $100 \mu \mathrm{M}$. Number of clearance periods studied in each group is shown in Table I. CLr/GFR represents the renal clearance of furosemide corrected for glomerular filtration rate. CLs/GFR represents the secretion clearance of furosemide corrected for glomerular filtration rate ( $C L s / G F R$ was calculated as $C L r / G F R$ $f u) . C L r /(f u \cdot G F R)$ represents the excretion ratio, which is the renal clearance of furosemide corrected for the fraction unbound in the perfusate and glomerular filtration rate.

to increase as the unbound fraction increases. However, they do so in a nonproportional manner, implying that the renal transport of furosemide may be complicated by a capacity-limited secretory component. This finding is further supported by the values for excretion ratio, which indicate a reduction in net secretion (from 60.8 to 8.72 ) as the fraction unbound becomes greater. Preliminary inspection of the data revealed that the renal mechanisms of furosemide transport may be even more complex (Figs. 1 and 2). Both Figs. 1 and 2 appear to have a prominent $y$ intercept as well as a convex ascending curve. To be consistent with the underlying assumptions of Eq. (5) or (6), a plot of secretion clearance versus percent free would have to be a straight line with a zero $y$ intercept or remain a constant value, respectively. This led us to suspect that the renal tubular secretion of furosemide may involve two different transport mechanisms over the 


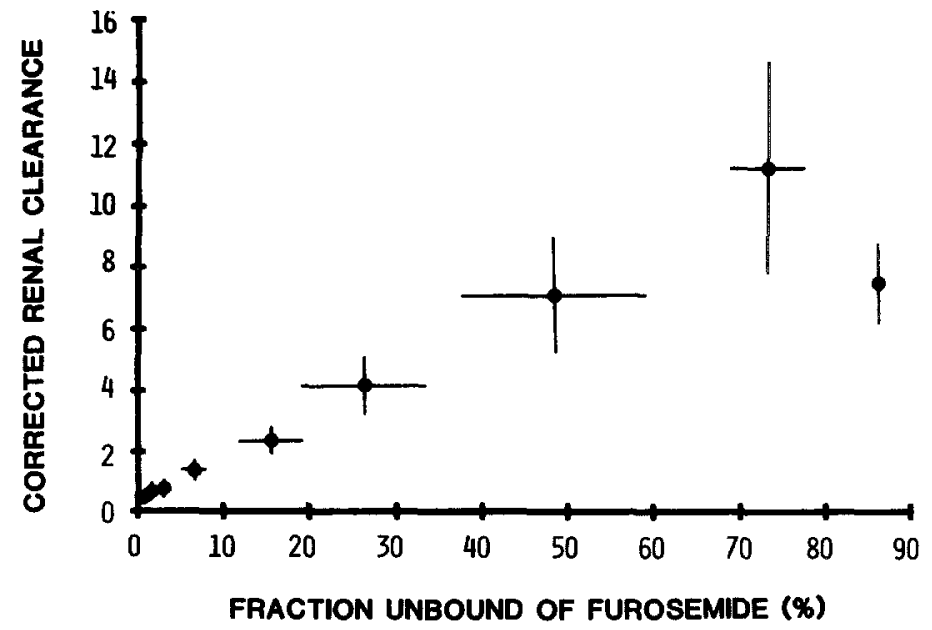

Fig. 1. Relationship between corrected renal clearance $(C L r / G F R)$ and fraction unbound $(f u)$ of furosemide in the isolated, perfused rat kidney. Each point represents the mean \pm SD of clearance periods for each experimental group (refer to Tables II and III).

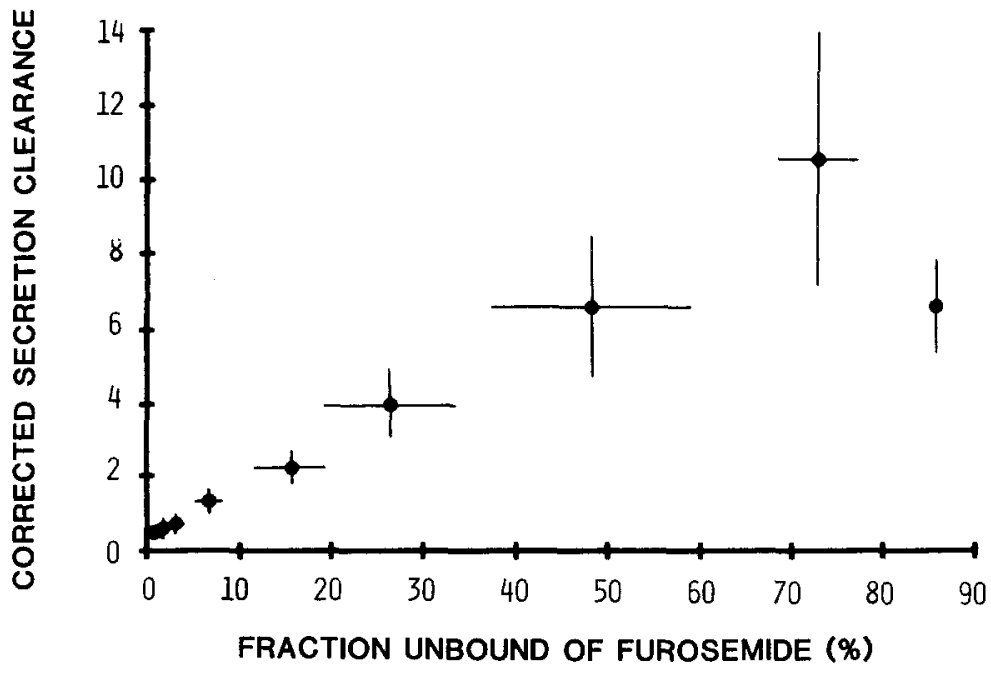

Fig. 2. Relationship between corrected secretion clearance (CLS/GFR) and fraction unbound $(f u)$ of furosemide in the isolated, perfused rat kidney. Each point represents the mean \pm SD of clearance periods for each experimental group (refer to Tables II and III). 
concentration range studied. The experimental evidence in support of this hypothesis is presented below.

The relationship between excretion ratio and unbound concentration of furosemide in the isolated, perfused rat kidney is shown in Fig. 3. Using the input values $E R$ and $C f$, we estimate the unknown parameters of Eq. (12) $\left(V m_{1} / G F R\right.$ as $P_{1}, K m_{1}$ as $P_{2}$, and $V m_{2} / G F R$ as $P_{3} ; F=0$; see discussion) as $P_{1}=357(190) \mu \mathrm{M}, K m_{1}=27.1(17.6) \mu \mathrm{M}$, and $P_{3}=22.5$ (1.5) $\mu \mathrm{M}\left(R^{2}=0.940 ; C O R=0.888\right)$. The values of $V m_{1}(278 \mathrm{nmole} / \mathrm{min})$ and $V m_{2}(17.5 \mathrm{nmole} / \mathrm{min})$ were calculated by multiplying $P_{1}$ and $P_{3}$ by the mean value for GFR $(0.778 \mathrm{ml} / \mathrm{min})$. As observed in Fig. 3, the data are compatible with the proposed model in which furosemide secretion is described by two distinct transport processes.

The data were also fitted to Eq. (13), in which the relationship between urinary excretion rate and unbound concentration of furosemide in the isolated, perfused rat kidney was examined (Fig. 4). Using the input values $U \cdot \dot{V}$ and $C f$ and a mean value of $0.778 \mathrm{ml} / \mathrm{min}$ for $G F R$ in the right side of the equation, we estimate the unknown parameters $\left(V m_{1}\right.$ as $P_{1}, K m_{1}$ as $P_{2}$, and $V m_{2}$ as $P_{3} ; F=0$; see discussion) as $V m_{1}=300(53.9) \mathrm{nmole} / \mathrm{min}$, $K m_{1}=39.8(12.4) \mu \mathrm{M}$, and $V m_{2}=22.1(2.7) \mathrm{nmole} / \mathrm{min}\left(R^{2}=0.937 ; C O R=\right.$ 0.917). Application of Eq. (13) resulted in smaller coefficients of variation than Eq. (12) for $P_{1}$ and $P_{2}$, but not $P_{3}$. These differences probably reflect the inherent bias produced by data transformation and consequently weighting. Still, both of these equations (12) and (13) afforded reasonable estimates

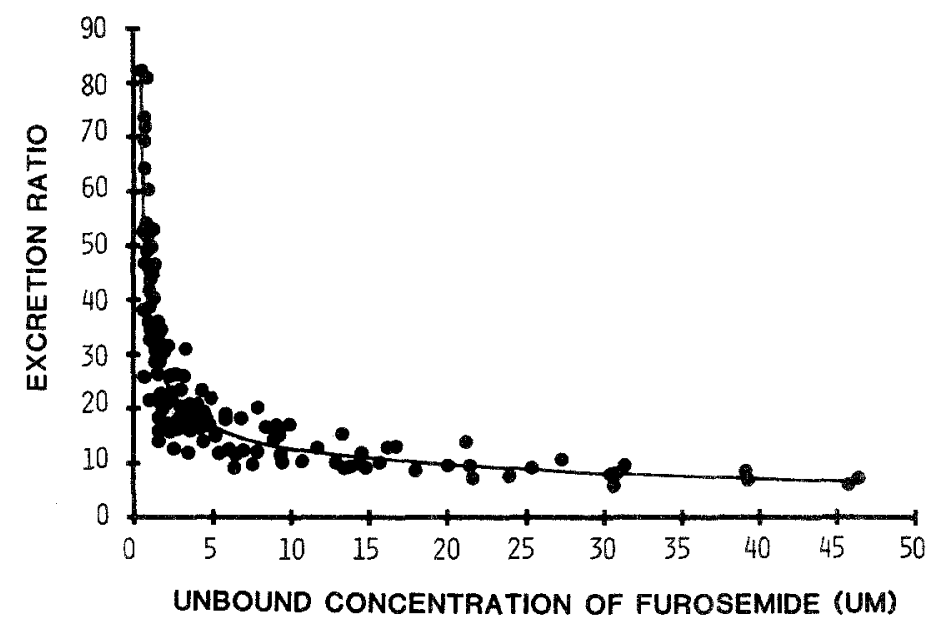

Fig. 3. Relationship between excretion ratio $(E R)$ and unbound concentration of furosemide $(C f)$ in the isolated, perfused rat kidney. All 155 clearance periods from 20 experiments are depicted. The solid line represents the computer-simulated curve based on the fitted parameters of Eq. (12). 


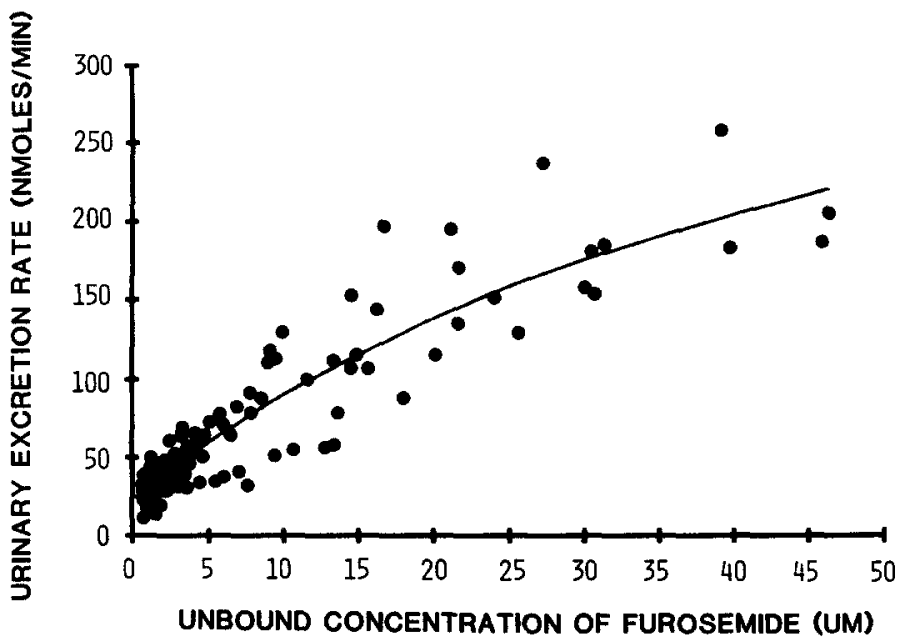

Fig. 4. Relationship between urinary excretion rate $(U \cdot \dot{V})$ and unbound concentration of furosemide $(C f)$ in the isolated, perfused rat kidney. All 155 clearance periods from 20 experiments are depicted. The solid line represents the computer-simulated curve based on the fitted parameters of Eq. (13).

of the renal transport parameters of furosemide and support the hypothesis that furosemide secretion may be operating by two different mechanisms. While an equivalent mathematical relationship can be derived for the high-affinity, low-capacity transport term in Eq. (12) or (13) when the driving force is total drug, this theory is inconsistent with the data recently reported by Hall and Rowland (2).

\section{DISCUSSION}

Utilizing the isolated, perfused rat kidney, Bowman (1) demonstrated that the ability of the renal secretory mechanism to extract ${ }^{35} \mathrm{~S}$-labeled furosemide from the perfusate was closely related to the concentration of unbound drug. At a perfusate concentration of $500 \mu \mathrm{M}$ furosemide, secretion of the drug was doubled when the albumin concentration was decreased from 7.5 to $5 \mathrm{~g} / 100 \mathrm{ml}$ (corresponding to a percent unbound of 2.19 and 3.15, respectively). Secretion was again doubled when the albumin concentration was further decreased to $2.5 \mathrm{~g} / 100 \mathrm{ml}$ (corresponding to a percent unbound of 9.4). Although these changes in net furosemide secretion are in the same direction as changes in percent unbound, they are not always of the same magnitude. Similar findings were reported by Koschier and Acara (3) when studying the transport of ${ }^{14} \mathrm{C}$-labeled trichlorophenoxyace- 
tate $(2,4,5-T)$ in the isolated, perfused rat kidney. These authors concluded that the secretion of 2,4,5-T appears to be hindered by plasma protein binding. At an initial perfusate concentration of $1.86 \mu \mathrm{M}$, the $2,4,5-\mathrm{T} /$ inulin clearance ratio increased over 300 -fold [from 0.019 in BSA $(6 \%)$ perfusate to 6.16 in dextran $(4 \%)$ perfusate] when the percent free increased 150 -fold (from 0.46 to 70.7 ). Again, a nonproportional change was observed between the extent of plasma protein binding and the renal clearance of $2,4,5-\mathrm{T}$, as was the case for furosemide. These findings may reflect the fact that perfusion experiments were performed with a limited number of free fraction values (1) or only at the extremes of protein binding (3). Renal tubular secretion may also be exhibiting capacity-limited transport at the concentrations being studied (1).

Recently, Hall and Rowland (2) reported data on the renal and secretion clearances of $\left[{ }^{14} \mathrm{C}\right]$ furosemide, referenced to total and unbound drug concentrations, in the isolated, perfused rat kidney. Using various combinations of albumin and dextran, these investigators observed a linear relationship between the renal clearance of furosemide and free fraction. Furthermore, when the fraction unbound was zero, the $y$ intercept was not significantly different from zero. Their data are consistent with the model expressed by Eq. (5), and support the view that for drugs that are actively secreted and of low renal extraction, the renal and secretory clearances are directly proportional to the fraction unbound. As a result, the excretion ratio of furosemide, which averaged approximately 4.6 , was relatively constant over the 28 -fold range of free fraction values, indicating a linear secretory mechanism. Discrepancies between our study and that of Hall and Rowland (2) probably reflect the fact that different concentrations of furosemide were employed. In our study, initial perfusate samples contained $100 \mu \mathrm{M}$ of furosemide, whereas very low and nonpharmacologic concentrations of furosemide $(<5 \mu \mathrm{M})$ were perfused in the study by Hall and Rowland (2). In addition, the latter study did not correct for the volume shifts that can occur during equilibrium dialysis (23), thereby causing systematic errors in the furosemide free fraction. Although we show a similar dependence of renal drug transport on free concentrations of furosemide, our data were complicated by the presence of capacity-limited secretion and by the appearance of more than one secretory transport system.

As previously mentioned, we observed a general reduction in GFR and perfusate flow in our experiments at lower albumin concentrations. Bowman et al. (27) in perfused rat kidneys and Duarte et al. (28) in micropuncture experiments in the rat also showed a fall in GFR as furosemide reached the urine in pharmacologically significant concentrations. Although both investigators state that the reason for the decline in $G F R$ is unclear, they suggest that it may be due to an increased intratubular 
pressure which develops after the drug-induced reduction in tubular sodium and fluid reabsorption. However, in our studies the fractional sodium excretion was relatively constant as a function of albumin concentration, making this an unlikely explanation for the observed attenuation in GFR. Alternatively, it is possible that increasing amounts of urinary furosemide caused a redistribution of intrarenal blood (perfusate) flow to the midcortical nephrons $(29,30)$. This could result in a reduction in the number of functioning nephrons, since this region comprises only $30 \%$ of the total nephron population (31). Nevertheless, clearance values (CLr/GFR, CLs/GFR, $E R$ ) were corrected for $G F R$ to take into account the varying functionality between kidney preparations. This approach to the treatment of the data minimizes the chance of the two-component active secretory system being a result of declining renal function. Further support for the validity of our model (i.e., two different transport systems for active secretion) is afforded when the furosemide data of Bowman (1) are superimposed upon the computer-generated regression line of Eq. (12). As shown in Fig. 5, the curves are remarkably similar even though a different study design and assay method were employed during the perfusion experiments. It should be noted that either no change or an increase in GFR was observed by Bowman (1) as the percent albumin was reduced.

Previous studies by Hori and co-workers (32-34) demonstrated that the renal tubular secretion of phenolsulfonphthalein, sulfamethizole, sulfamethoxazole, cephalexin, and ampicillin correlates with unbound drug concentrations. Their data were best fitted to a model in which only one

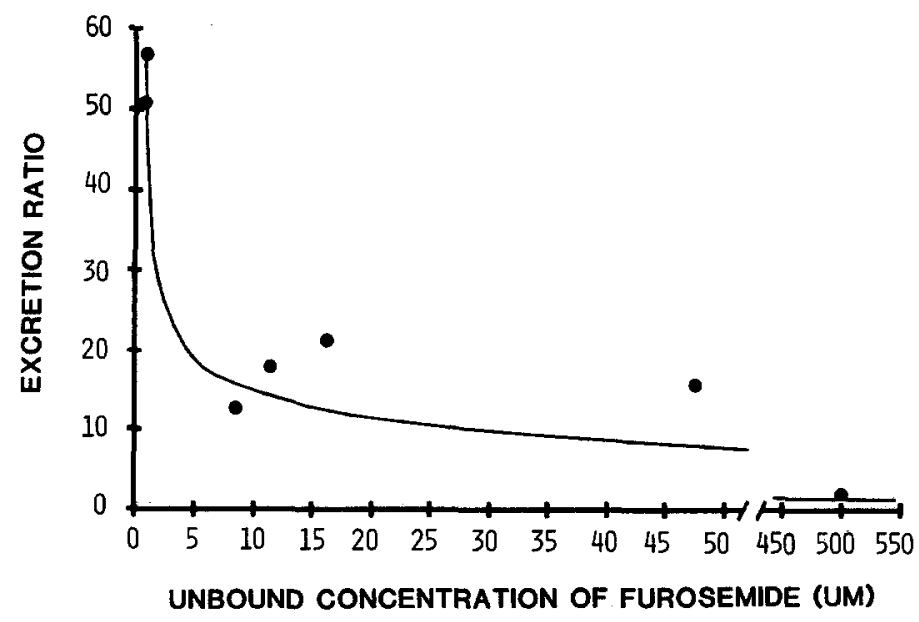

Fig. 5. Furosemide data of Bowman (1) superimposed upon the computergenerated regression line of Eq. (12) (see Fig. 3). 
Michaelis-Menten term describes renal tubular transport, and secretion rate is dependent upon free concentrations of drug in the plasma:

$$
E R=\left(1+\frac{V m / G F R}{K m+C f}\right)(1-F)
$$

Our results did not fit this model very well, as shown in Figs. 6 and 7. Using different initial estimates for the renal transport parameters, the computerfitted curves displayed a marked and systematic deviation from the data in addition to having greater values for the residual sum of squares $(61,578$ in Fig. 6A and 10,824 in Fig. 6B versus 8869 in Fig. 3; 8423 in Fig. 7 versus 6270 in Fig. 4). The discrepancy between our study with furosemide and those of Hori and co-workers (32-34) may reflect the different drugs examined. However, the unbound concentrations in their studies ranged from approximately 30 to $1500 \mu \mathrm{M}$, a value where the influence of the high-affinity, low-capacity transport system is minimal at best. Therefore, they may have been unable to detect, if existent, this second transport system.

Interpretation of the data is based on the assumption that the reabsorption fraction $F$ remains constant during and between experiments. In our analysis of the furosemide data we assumed that $F$ was equal to zero. This was done for several reasons. First, Bowman (1) demonstrated that in the presence and absence of albumin, probenecid reduced the renal clearance

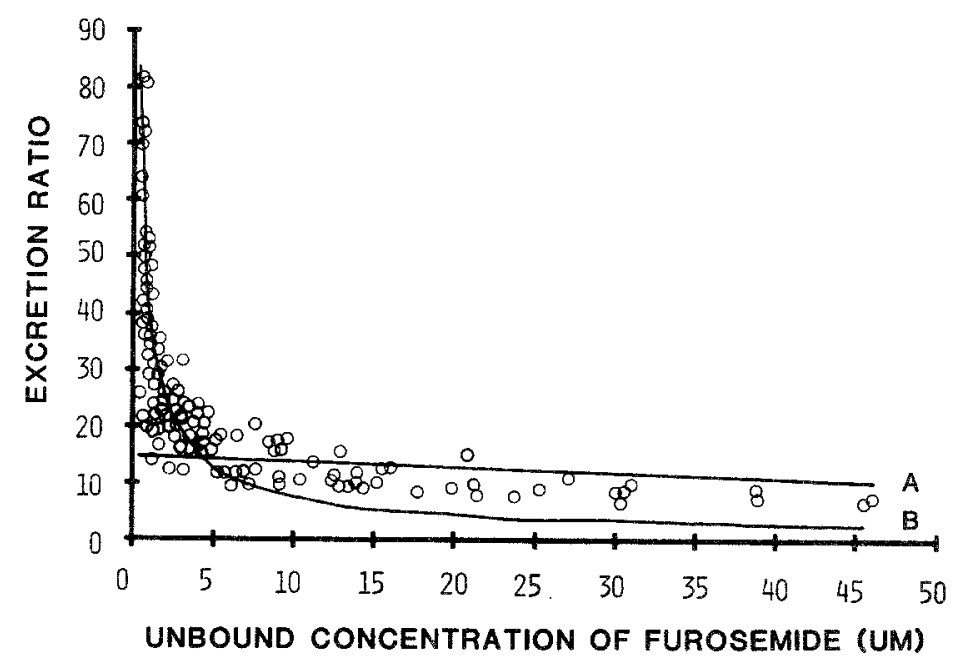

Fig. 6. Computer-generated regression curves of Eq. (14) (one MichaelisMenten term used to describe secretion) superimposed upon the furosemide excretion ratio data of Fig. 3. The lines A and B were obtained using different initial estimates for the renal transport parameters. 


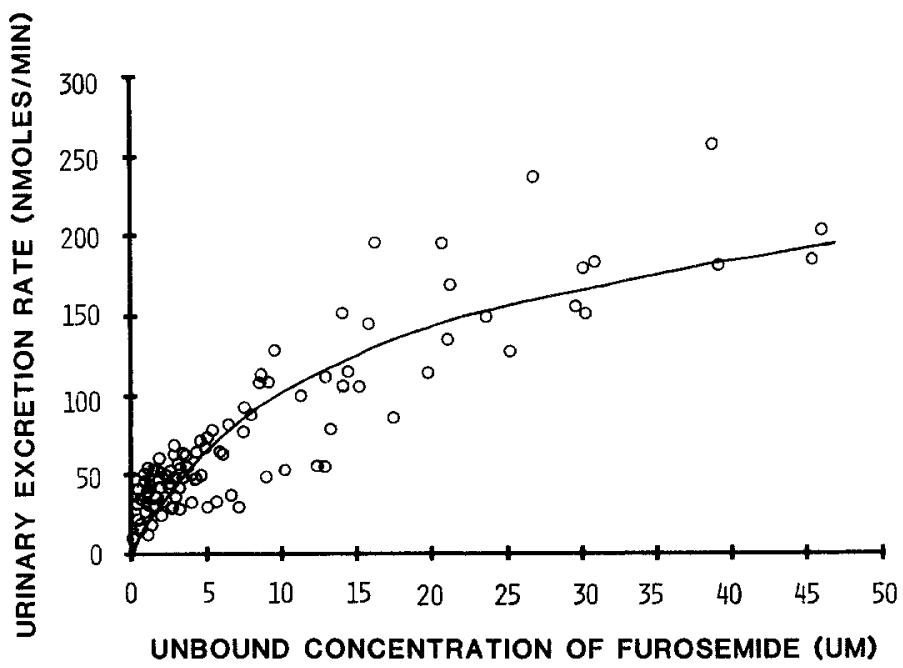

Fig. 7. Computer-generated regression curve using only a single MichaelisMenten term in Eq. (13) for describing the active secretion of furosemide. This line was superimposed upon the furosemide excretion rate data of Fig. 4.

of furosemide to that expected from filtration alone. This suggests that the extent of furosemide reabsorption is minimal at best in the isolated, perfused rat kidney. Second, we also fitted our data to the transport models expressed by Eqs. (12) and (13) where $F$ was allowed to be an unknown parameter. Regardless of the initial estimates provided, $F$ was computed as zero. Third, at the urinary $p \mathrm{H}$ values observed in our studies (mean of $6.9 ; \mathrm{CV}$ of $5.5 \%$ ) and given that the $p K_{a}$ of furosemide is 3.9 (35), the fraction of total drug nonionized would be insignificant. These facts, plus the lack of either a urine flow or $p \mathrm{H}$ effect on furosemide renal clearance, indicate that in these experiments reabsorption is not a significant mechanism of renal transport for this drug (2).

The present study has attempted to integrate quantitative data with a corresponding model for the renal transport of furosemide. Our results demonstrate that the renal mechanisms of furosemide excretion are more complex than previously reported $(1,2)$. Specifically, we show that the renal tubular secretion of furosemide may involve two different transport mechanisms over the concentration range studied. One secretory site is consistent with a high-affinity, low-capacity transport and the other with a low-affinity, high-capacity transport. Although speculative, these different transport mechanisms may reflect the morphological and functional heterogeneity of the proximal tubule cells $(36,37)$. 


\section{ACKNOWLEDGMENTS}

We thank Meera Goyal and Batul Hamid for teaching us the isolated, perfused rat kidney technique, and Dr. R. Tannen for his support and helpful advice in this endeavor.

\section{REFERENCES}

1. R. H. Bowman. Renal secretion of ${ }^{35}$ S-furosemide and its depression by albumin binding. Am. J. Physiol. 229:93-98 (1975).

2. S. Hall and $M$. Rowland. Influence of fraction unbound upon the renal clearance of furosemide in the isolated perfused rat kidney. $J$. Pharmacol. Exp. Ther. 232:263-268 (1985).

3. F. J. Koschier and M. Acara. Transport of 2,4,5-trichloroacetate in the isolated, perfused rat kidney. J. Pharmacol. Exp. Ther. 208:287-293 (1979).

4. G. Levy. Effect of plasma protein binding on renal clearance of drugs. J. Pharm. Sci. 69: 482-483 (1980).

5. S. Øie and L. Z. Benet. Altered drug disposition in disease states. Annu. Rep. Med. Chem. 15:277-287 (1980).

6. I. M. Weiner. Excretion of drugs by the kidney. In B. B. Brodie and J. R. Gillette (eds.), Handbook of Experimental Pharmacology, Vol, 28, Part 1, Springer, Berlin, 1971, pp. $328-353$.

7. I. M. Weiner. Transport of weak acids and basis. In J. Orloff and R. W. Berliner (eds.), Handbook of Physiology, Section 8, Renal Physiology, American Physiological Society, Washington, D.C., 1973, pp. 521-554.

8. L. Z. Benet. Pharmacokinetics/pharmacodynamics of furosemide in man: A review. $J$. Pharmacokin. Biopharm. 7:1-27 (1979).

9. R. E. Cutler and A. D. Blair. Clinical pharmacokinetics of furosemide. Clin Pharmacokinet. 4:279-296 (1979).

10. K. E. Kim, G. Onesti, J. H. Moyer, and C. Swartz. Ethacrynic acid and furosemide: Diuretic and hemodynamic effects and clinical uses. Am. J. Cardiol, 27:407-415 (1971).

11. W. M. Kirkendall and J. H. Stein. Clinical pharmacology of furosemide and ethacrynic acid. Am. J. Cardiol. 22:162-167 (1968).

12. W. B. Stason, P. J. Cannon, H. O. Heinemann, and J. H. Laragh. Furosemide: A clinical evaluation of its diuretic action. Circulation 34:910-920 (1966).

13. P. Chennavasin, R. Seiwell, D. C. Brater, and W. M. M. Liang. Pharmacodynamic analysis of the furosemide-probenecid interaction in man. Kidney Int. 16:187-195 (1979).

14. T. P. Green and B. L. Mirkin. Resistance of proteinuric rats to furosemide: Urinary drug binding as a determinant of drug effect. Life Sci. 26:623-630 (1980).

15. D. E. Smith and L. Z. Benet. Relationship between urinary excretion rate, steady-state plasma levels and diuretic response of furosemide in the rat. Pharmacology 19:301-306 (1979).

16. H. A. Krebs and K. Henseleit. Untersuchungen uber die harnstoffbildung im tierkorper. Z. Physiol. Chem. 210:33-66 (1932).

17. I. Bekersky. Use of the isolated perfused kidney as a tool in drug disposition studies. Drug Metab. Rev. 14:931-960 (1983).

18. J. M. Nishiitsutsuji-Uwo, B. D. Ross, and H. A. Krebs. Metabolic activities of the isolated perfused rat kidney. Biochem. J. 103:852-862 (1967).

19. R. H. Bowman. The perfused rat kidney. Meth. Enzymol. 39:3-11 (1975).

20. D. E. Smith, E. T. Lin, and L. Z. Benet. Absorption and disposition of furosemide in healthy volunteers, measured with a metabolite-specific assay. Drug Metab. Dispos. 8:337. 342 (1980).

21. D. E. Smith and L. Z. Benet. Plasma protein binding of furosemide in kidney transplant patients. J. Pharmacokin. Biopharm. 10:663-674 (1982). 
22. H. L. Behm and J. G. Wagner. Errors in interpretation of data from equilibrium dialysis protein binding experiments. Res. Commun. Chem. Pathol. Pharmacol. 26:145-160 (1979).

23. T. N. Tozer, J. G. Gambertoglio, D. E. Furst, D. S. Avery, and N. H. G. Holford. Volume shifts and protein binding estimates using equlibrium dialysis: Application to prednisolone binding in humans. J. Pharm. Sci. 72:1442-1446 (1983).

24. C. M. Metzler. NONLIN, A Computer Program for Parameter Estimation in Nonlinear Situations. Upjohn Co., Kalamazoo, Michigan 1969.

25. B. D. Ross. The isolated perfused rat kidney. Clin. Sci. Mol. Med. 55:513-521 (1978).

26. D. C. Brater and S. O. Thier. Renal disorders. In K. L. Melmon and H. F. Morrelli (eds.), Clinical Pharmacology: Basic Principles in Therapeutics, 2nd ed., Macmillan, New York, 1978, pp. 349-387.

27. R. H. Bowman, J. Dolgin, and R. Coulson. Furosemide, ethacrynic acid, and iodoacetate on function and metabolism in perfused rat kidney. Am. J. Physiol. 224:416-424 (1973).

28. C. G. Duarte, F. Chomety, and G. Giebisch. Effect of amiloride, ouabain, and furosemide on distal tubular function in the rat. Am. J. Physioi 221:632-639 (1971).

29. J. H. Stein, R. C. Mauk, S. Boonjarern, and T. F. Ferris. Differences in the effect of furosemide and chlorothiazide on the distribution of renal cortical blood flow in the dog. J. Lab. Clin. Med. 79:995-1003 (1972).

30. M. D. Bailie, J. A. Barbour, and J. B. Hook. Effects of indomethacin on furosemide-induced changes in renal blood flow. Proc. Soc. Exp. Biol. Med. 148:1173-1176 (1975).

31. E. M. Renkin and J. P. Gilmore. Glomerular filtration. In J. Orloff and R. W. Berliner (eds.), Handbook of Physiology, Section 8, Renal Physiology, American Physiological Society, Washington, D. C., 1973, pp. 185-248.

32. R. Hori, K. Sunayashiki, and A. Kamiya. Tissue distribution and metabolism of drugs. I. Quantitative investigation on renal handling of phenolsulfonphthalein and sulfonamides in rabbits. Chem. Pharm. Bull. 26:740-745 (1978).

33. R. Hori, K. Okumura, A. Kamiya, H. Nihira, and H. Nakano. Ampicillin and cephalexin in renal insufficiency. Clin. Pharmacol. Ther. 34:792-798 (1983).

34. A. Kamiya, K. Okumura, and R. Hori. Quantitative investigation on renal handling of drugs in rabbits, dogs, and humans. J. Pharm. Sci. 72:440-443 (1983).

35. V. P. Hajdú and A. Häussler. Untersuchungen mit dem salidiureticum 4-chloro- $N$-(2furylmethyl)-5-sulfamylanthranilsäure, I. Arzneim. Forch. 14:709-710 (1964).

36. J. J. Grantham and J. Irish. Organic transport and fluid secretion in the pars recta (PST) of the proximal tubule. In H. G. Vogel and K. J. Ullrica (eds.), New Aspects of Renal Function, Excerpta Medica, Amsterdam, 1978, pp. 83-87.

37. M. A. Venkatachalam, D. B. Bernard, J. F. Donahope, and N. G. Levinsky. Ischemic damage and repair in the rat proximal tubule: Differences among the $S 1, S 2$, and $S 3$ segments. Kidney Int. 14:31-49 (1978). 